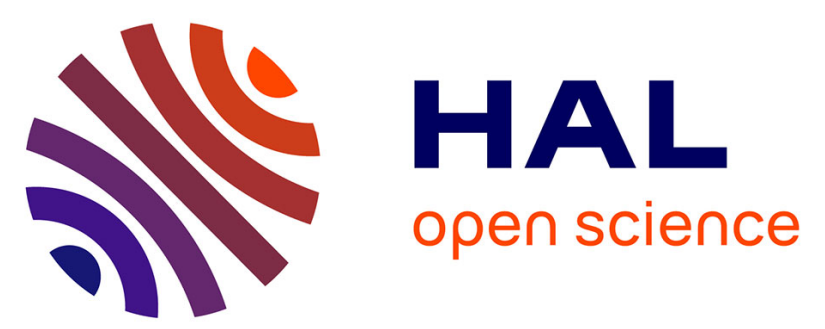

\title{
In vitro interference of $\beta$-lactams with biofilm development by prevalent community respiratory tract isolates
}

J.R. Maestre, M. Mateo, M.L. Méndez, L. Aguilar, M.J. Gimenez, L. Alou, P. Coronel, J.J. Granizo, J. Prieto

\section{To cite this version:}

J.R. Maestre, M. Mateo, M.L. Méndez, L. Aguilar, M.J. Gimenez, et al.. In vitro interference of $\beta$-lactams with biofilm development by prevalent community respiratory tract isolates. International Journal of Antimicrobial Agents, 2010, 35 (3), pp.274. 10.1016/j.ijantimicag.2009.10.020 . hal00556382

\section{HAL Id: hal-00556382 https://hal.science/hal-00556382}

Submitted on 16 Jan 2011

HAL is a multi-disciplinary open access archive for the deposit and dissemination of scientific research documents, whether they are published or not. The documents may come from teaching and research institutions in France or abroad, or from public or private research centers.
L'archive ouverte pluridisciplinaire HAL, est destinée au dépôt et à la diffusion de documents scientifiques de niveau recherche, publiés ou non, émanant des établissements d'enseignement et de recherche français ou étrangers, des laboratoires publics ou privés. 


\section{Accepted Manuscript}

Title: In vitro interference of $\beta$-lactams with biofilm

development by prevalent community respiratory tract isolates

Authors: J.R. Maestre, M. Mateo, M.L. Méndez, L. Aguilar, M.J. Gimenez, L. Alou, P. Coronel, J.J. Granizo, J. Prieto

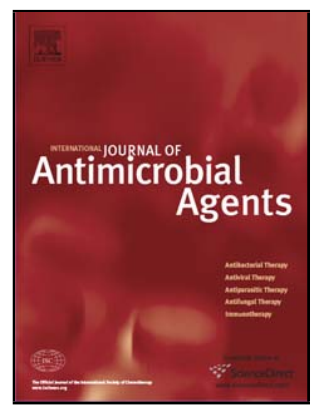

PII:

S0924-8579(09)00507-X

DOI:

doi:10.1016/j.ijantimicag.2009.10.020

Reference:

ANTAGE 3175

To appear in:

International

Journal

of

Antimicrobial

Agents

Received date: $\quad$ 19-6-2009

Revised date: $\quad 15-9-2009$

Accepted date: $\quad$ 26-10-2009

Please cite this article as: Maestre JR, Mateo M, Méndez ML, Aguilar L, Gimenez MJ, Alou L, Coronel P, Granizo JJ, Prieto J, In vitro interference of $\beta$-lactams with biofilm development by prevalent community respiratory tract isolates, International Journal of Antimicrobial Agents (2008), doi:10.1016/j.jantimicag.2009.10.020

This is a PDF file of an unedited manuscript that has been accepted for publication. As a service to our customers we are providing this early version of the manuscript. The manuscript will undergo copyediting, typesetting, and review of the resulting proof before it is published in its final form. Please note that during the production process errors may be discovered which could affect the content, and all legal disclaimers that apply to the journal pertain. 


\title{
In vitro interference of $\beta$-lactams with biofilm development by prevalent community respiratory tract isolates
}

\author{
J.R. Maestre ${ }^{\text {a }}$, M. Mateo ${ }^{\text {a }}$, M.L. Méndez ${ }^{\text {a }}$, L. Aguilar ${ }^{\text {b, }}$, M.J. Gimenez ${ }^{b}$, L. Alou \\ ${ }^{b}$, P. Coronel ${ }^{c}$, J.J. Granizo ${ }^{d}$, J. Prieto ${ }^{b}$
}

${ }^{a}$ Microbiology Department, Hospital Central de la Defensa Gómez-Ulla, Gta. del Ejército s/n, 28007 Madrid, Spain

${ }^{\mathrm{b}}$ Microbiology Department, School of Medicine, Universidad Complutense, Avda. Complutense s/n, 28040 Madrid, Spain

${ }^{c}$ Scientific Department, Tedec-Meiji Farma S.A., Ctra. M-300, Km 30,500, 28802 Alcalá de Henares, Madrid, Spain

' Grana Datos SL, Demetrio de la Guerra 4, 28223 Pozuelo de Alarcón, Madrid, Spain

\section{ARTICLE INFO}

Article history:

Received 19 June 2009

Accepted 26 October 2009

Keywords:

Slime

Streptococcus pneumoniae

Haemophilus influenzae

Cefditoren 
Amoxicillin/clavulanic acid

* Corresponding author. Tel.: +34 913941 505; fax: +34 913941511.

E-mail address: laguilar@med.ucm.es (L. Aguilar).

is Part of this study was presented at the 19th European Congress of Clinical Microbiology and Infectious Diseases (ECCMID), 16-19 May 2009, Helsinki, Finland. 


\section{ABSTRACT}

Interference of cefditoren (CDN) and amoxicillin/clavulanic acid (AMC) with biofilm production was studied using 11 Streptococcus pneumoniae isolates with minimum inhibitory concentrations (MICs) ranging from $0.015 \mu \mathrm{g} / \mathrm{mL}$ to $0.5 \mu \mathrm{g} / \mathrm{mL}$ for CDN and from $0.06 \mu \mathrm{g} / \mathrm{mL}$ to $2 \mu \mathrm{g} / \mathrm{mL}$ for AMC (except for one isolate with an AMC MIC of $8 \mu \mathrm{g} / \mathrm{mL}$ ) and 5 Haemophilus influenzae isolates with MICs of $0.03-$ $0.06 \mu \mathrm{g} / \mathrm{mL}$ for $\mathrm{CDN}$ and $0.5-16 \mu \mathrm{g} / \mathrm{mL}$ for AMC. Slime production was assessed in antibiotic-free medium and with $0.03 \mu \mathrm{g} / \mathrm{mL}$ CDN or $1 / 0.5 \mu \mathrm{g} / \mathrm{mL}$ AMC by measuring the optical density at $450 \mathrm{~nm}\left(\mathrm{OD}_{450}\right)$. Significantly lower mean $\mathrm{OD}_{450}$ values were obtained for $S$. pneumoniae with antibiotics compared with controls (CDN, 0.088 vs. $0.118, P=0.003$; and AMC, 0.095 vs. $0.112, P=0.003$ ), with significant correlation between both antibiotics $(r=0.752 ; P=0.008)$. Percent reduction in $\mathrm{OD}_{450}$ values was higher for CDN compared with $\mathrm{AMC}(24.02 \%$ vs. $15.92 \% ; P=0.008$ ). For $H$. influenzae, significantly lower mean $\mathrm{OD}_{450}$ values were obtained with CDN compared with controls (0.083 vs. $0.096 ; P=0.043)$ but not with $\mathrm{AMC}(0.086$ vs. $0.095 ; P=0.08)$. Comparing percent reductions in $S$. pneumoniae versus $H$. influenzae for each antibiotic, no differences were found for AMC $(15.92 \%$ vs. $9.40 \%$; $P=0.36)$, with a tendency for CDN $(24.02 \%$ vs. $13.79 \%$; $P=0.069)$. Different $\beta$-lactams may have different capabilities of interfering with $S$. pneumoniae biofilm development when tested under the same experimental conditions. 


\section{Introduction}

Chronic ailments caused by normal commensal flora are now prevalent infectious diseases [1]. These types of microorganisms, such as Streptococcus pneumoniae and Haemophilus influenzae, which form part of the nasopharyngeal microbiota, make full use of the biofilm strategy when causing non-invasive disease. Biofilms are 'a structured community of bacterial cells enclosed in a self-produced polymeric matrix adherent to an inert or living surface' [2]. Alterations in the metabolism of biofilm bacteria make them difficult to recover with standard culture techniques [1] as well as more resistant to antibiotic therapy than planktonic bacteria [3]. Thus, bacterial biofilms play a relevant role in chronic infections such as sinusitis, chronic otitis, otitis media with effusion and chronic bronchitis, where antibiotic therapy may overcome the symptoms caused by waves of planktonic cells released from the biofilm during exacerbations of the disease but fails to eradicate infection as sessile cells are inherently less affected [4]. Owing to these facts, not only is time to eradication of symptoms an endpoint in clinical trials with antibiotics against exacerbations, but time to relapse is also increasingly used.

Streptococcus pneumoniae and $H$. influenzae are the most prevalent bacterial isolates in the abovementioned infections. Specific resistance phenotypes have been described in these two species: (a) high resistance to macrolides in $S$. pneumoniae owing to the prevalent macrolide-lincosamide-streptogramin B $\left(\mathrm{MLS}_{\mathrm{B}}\right)$ phenotype, implying high-level resistance (that cannot be overcome by increasing doses) [5]; (b) amoxicillin resistance related to specific clones among penicillin-resistant $S$. pneumoniae [6]; and (c) $\beta$-lactamase production and the recently increasing $\beta$-lactamase-negative ampicillin-resistant (BLNAR) and $\beta$ - 
lactamase-positive amoxicillin/clavulanic acid-resistant (BLPACR) phenotypes in H. influenzae [7]. Despite these facts, oral penicillins, cephalosporins and macrolides are commonly used antibiotics to treat the these infections.

It has been hypothesised that compounds active against not only planktonic cells but also able to interfere or decrease biofilm development by these two capsulated bacteria may offer clinical advantages [8]. Cefditoren (CDN) is an oral thirdgeneration cephalosporin with high intrinsic activity against $S$. pneumoniae [9] and H. influenzae [7] in planktonic cultures regardless of the resistance phenotype. The aim of this study was to assess whether CDN [compared with amoxicillin/clavulanic acid (AMC)] is able to interfere with the ability of $S$. pneumoniae and $H$. influenzae to produce biofilms.

\section{Material and methods}

\subsection{Strains}

\subsubsection{Streptococcus pneumoniae}

Among 40 recent clinical isolates from non-invasive samples kindly supplied by the Spanish Reference Pneumococcal Laboratory (Instituto de Salud Carlos III, Majadahonda, Madrid, Spain), 12 isolates were chosen on the basis of their capability of biofilm production, spectrophotometrically measured, defined as an optical density at $450 \mathrm{~nm}\left(\mathrm{OD}_{450}\right) \geq 0.08$, the value corresponding to the $\mathrm{OD}_{450}$ produced by strain R6 (see below). Among the group of isolates producing biofilm, the 12 isolates were chosen based on their susceptibility to penicillin in order to 
have $75 \%$ of them non-susceptible to penicillin according to Clinical and Laboratory Standards Institute (CLSI) breakpoints for oral penicillin [10].

\subsubsection{Haemophilus influenzae}

Among 40 recent clinical isolates from non-invasive samples kindly supplied by six Spanish hospitals in a previous study [7], 12 isolates were chosen on the basis of their capability of biofilm production, spectrophotometrically measured, defined as an $\mathrm{OD}_{450} \geq 0.08$ (see below). Among the group of isolates producing biofilm, the 12 isolates were chosen based on their susceptibility to ampicillin in order to have $75 \%$ of them non-susceptible to ampicillin according to CLSI breakpoints [10].

\subsection{Susceptibility testing}

Minimum inhibitory concentrations (MICs) of CDN and AMC were determined three times by the microdilution method following CLSI guidelines [11]. Modal values were considered.

\subsection{Biofilm production}

Biofilm production was assessed by a spectrophotometric method as described previously [12] using 96-well polystyrene microtitre plates (Masterlab S.L., Madrid, Spain). Briefly, in antibiotic-free experiments (controls), wells were inoculated with $200 \mu \mathrm{L}$ of a bacterial suspension in Haemophilus Test Medium (HTM) broth (Dade Behring, West Sacramento, CA), corresponding to $0.5 \mathrm{McF}$ arland standard, of $S$. pneumoniae strain R6 (strong slime producer), S. pneumoniae ATCC 6303 (negative slime producer) and each of the study strains. In experiments with 
antibiotics that were run in parallel, wells containing $50 \mu \mathrm{L}$ of antibiotic concentrations in HTM were inoculated with $150 \mu \mathrm{L}$ of bacterial suspension of study strains (0.5 McFarland standard) in HTM. Final antibiotic concentrations in the final $200 \mu \mathrm{L}$ volume were $0.03 \mu \mathrm{g} / \mathrm{mL}$ CDN and $1 / 0.5 \mu \mathrm{g} / \mathrm{mL}$ AMC (free concentrations achievable in serum after standard oral doses) [13]. Plates were covered and incubated at $37^{\circ} \mathrm{C}$ under a $5 \% \mathrm{CO}_{2}$ atmosphere for $24 \mathrm{~h}$. Following incubation, the contents of each well were removed by decantation and the wells were washed with sterile distilled water. The empty wells were allowed to dry for 30 min and then $200 \mu \mathrm{L}$ of crystal violet stain (25\%) was added to each well. After 5 min, the excess stain was rinsed off by decantation and the plate was washed. After the well had been allowed to dry for $30 \mathrm{~min}, 200 \mu \mathrm{L}$ of $\mathrm{HCl} 25 \%$ was added to each well and after 1 min the $O D_{450}$ of stained adherent bacterial films was read using a Micro-ELISA auto-reader spectrophotometer (Labsystems Multiskan, Helsinki, Finland). As a negative control, non-inoculated wells were subjected to the same procedures. Experiments with each strain were performed 12 times and mean values were considered.

\subsection{Statistical analysis}

Per-strain percentages of reduction in $\mathrm{OD}_{450}$ in the presence of antibiotics compared with controls (antibiotic-free wells) were calculated. Mean \pm standard deviation $\mathrm{OD}_{450}$ values for $S$. pneumoniae and $H$. influenzae strains were calculated for each antibiotic. Percentage reductions obtained with CDN and AMC as well as comparisons between $\mathrm{OD}_{450}$ values in antibiotic-free media and in the presence of antibiotics were compared using the Wilcoxon test. 
For each antibiotic, percentage reductions obtained for $S$. pneumoniae were compared with those obtained for $H$. influenzae using the Mann-Whitney test. Correlations of CDN and AMC reductions for each species were analysed using the Spearman correlation coefficient.

\section{Results}

Negative controls (non-inoculated wells and those inoculated with $S$. pneumoniae ATCC 6303) exhibited a mean $\mathrm{OD}_{450}$ of 0.053 , whilst the positive control $(S$. pneumoniae R6) exhibited a mean $\mathrm{OD}_{450}$ of 0.084 .

\subsection{Streptococcus pneumoniae}

At screening, among the 40 pneumococci tested, 19 (47.5\%) produced biofilms exhibiting $\mathrm{OD}_{450}$ values similar to or higher than that of R6. Among them, 12 pneumococci were chosen for the study: 3 were penicillin intermediate and 9 were fully resistant to penicillin [10]. One strain could not be further recovered. In the study phase, the remaining 11 strains exhibited an $\mathrm{OD}_{450}$ value ranging from 0.078 to 0.235 in antibiotic-free experiments (Table 1 ).

Table 1 shows the serotypes and susceptibility to CDN and AMC of pneumococcal study strains. All strains but one (strain 11) were susceptible to AMC, and the CDN MIC was $\leq 0.5 \mu \mathrm{g} / \mathrm{mL}$ in all cases. Table 1 also shows $\mathrm{OD}_{450}$ values for controls as well as percentage reduction by the presence of the antibiotics. 
In the CDN experiments, global mean $\mathrm{OD}_{450}$ values for $\mathrm{CDN}$-treated strains were significantly lower than those for controls $(0.088 \pm 0.039$ vs. $0.118 \pm 0.052 ; P=$ 0.003). Percentage reduction in $\mathrm{OD}_{450}$ by the presence of CDN ranged from $14.7 \%$ to $50.5 \%$ (Table 1$)$.

In experiments carried out with $A M C$, global mean $\mathrm{OD}_{450}$ values for $\mathrm{AMC}$ were significantly lower than those for controls $(0.095 \pm 0.053$ vs. $0.112 \pm 0.056 ; P=$ 0.003 ), although the reduction in the case of strain 4 was $<5 \%$. Excluding strain 4 , the percentage reduction in $\mathrm{OD}_{450}$ by the presence of $\mathrm{AMC}$ ranged from $8.5 \%$ to $36.7 \%$ (Table 1).

Comparing reductions in $\mathrm{OD}_{450}$ obtained with both antibiotics, a significantly higher global mean percentage reduction was obtained with CDN than with AMC (24.02 \pm $11.12 \%$ vs. $15.92 \pm 8.64 \% ; P=0.008)$, with high and significant correlation between the reductions obtained with both antibiotics $(r=0.752 ; P=0.008)$.

\subsection{Haemophilus influenzae}

Among the 40 strains tested, only 12 (30\%) produced biofilms exhibiting $\mathrm{OD}_{450}$ values similar to or higher than that of $S$. pneumoniae R6 and were chosen for the study. Of them, nine strains exhibited ampicillin non-susceptibility (MIC $\geq 2 \mu \mathrm{g} / \mathrm{mL}$ ): three strains were $\beta$-lactamase positive, four were BLNAR and two were BLPACR exhibiting mutations in the fts/gene [7]. Only 5 (41.7\%) of the 12 strains exhibited a decrease ( $>5 \%$ reduction) in $\mathrm{OD}_{450}$ in the presence of antibiotics, whether CDN or AMC. Phenotypically, three strains were susceptible to AMC (strains 1, 3 and 4) 
and two were resistant (strains 2 and 5) following the current CLSI breakpoints [10]. Table 2 shows the resistance genotypes and susceptibility of the five $H$. influenzae strains.

In the CDN experiments, global mean $\mathrm{OD}_{450}$ values for $\mathrm{CDN}$ were significantly lower than those for controls $(0.083 \pm 0.008$ vs. $0.096 \pm 0.008 ; P=0.043)$. Perstrain percentage reductions in $\mathrm{OD}_{450}$ compared with controls by the presence of CDN ranged from $6.1 \%$ to $23.1 \%$ (Table 2 ).

In experiments carried out with $\mathrm{AMC}$, global mean $\mathrm{OD}_{450}$ values were not significantly different from those for controls $(0.086 \pm 0.011$ vs. $0.095 \pm 0.006 ; P=$ 0.08).

Comparing reductions in $\mathrm{OD}_{450}$ obtained with both antibiotics, no significant differences were found between the global mean percentage reduction obtained with CDN versus AMC (13.79 \pm 6.65 vs. $9.40 \pm 9.38 ; P=0.5)$, with a weak and statistically non-significant correlation between the reductions obtained with both antibiotics $(r=0.300 ; P=0.624)$.

\subsection{Streptococcus pneumoniae versus Haemophilus influenzae}

When comparing per antibiotic global mean percentage reductions in $\mathrm{OD}_{450}$ between $S$. pneumoniae and $H$. influenzae, no differences were found for AMC $(15.92 \pm 8.60 \%$ vs. $9.40 \pm 9.38 \% ; P=0.36)$, with a tendency to higher percentage 
reductions in S. pneumoniae for CDN $(24.02 \pm 11.12 \%$ vs. $13.79 \pm 6.65 \%$; $P=$ 0.069).

\section{Discussion}

One of the major goals in modern clinical microbiology is the development of strategies capable of reducing biofilm infections related to chronic conditions owing to the difficulty of antibiotics in eradicating bacteria within these structures. In this regard, macrolides/azalides and quinolones have been shown to interfere with biofilm formation $[8,14]$, but the quinolones are not adequate in paediatric infections and resistance rates to azithromycin in S. pneumoniae and $H$. influenzae in Spain using pharmacokinetic/pharmacodynamic breakpoints [5] make them pharmacodynamically inadequate in the treatments of infections caused by these two microorganisms.

Whilst for highly charged antibiotics the glycocalyx affects their ability to reach bacterial cells that are deep within the biofilm, for $\beta$-lactams such limitation does not exist since they are uncharged agents [15]. Reduced susceptibility to $\beta$ lactams in biofilm bacteria is more related to the diminished growth rate in these structures, as in the case of $S$. pneumoniae ( $2-3 \mathrm{~h}$ for planktonic bacteria versus ca. $10 \mathrm{~h}$ in biofilms) [15]. Since $\beta$-lactams are widely used antibiotics, in the present study we explored the capability of suprainhibitory and subinhibitory physiologically achievable concentrations of a third-generation oral cephalosporin and AMC in interfering with biofilm formation in HTM media, since this media supported S. pneumoniae biofilm development better than trypticase soy broth or 
brain-heart infusion (data not shown). Owing to the higher intrinsic activity of CDN, a concentration of $0.03 \mu \mathrm{g} / \mathrm{mL}$ of this drug was tested and compared with a concentration of $1 / 0.5 \mu \mathrm{g} / \mathrm{mL}$ AMC.

When antibiotics were present in the media, significantly lower $\mathrm{OD}_{450}$ values were obtained for S. pneumoniae, with a significant correlation between both antibiotics in reducing biofilm formation. In any case, the reduction in $\mathrm{OD}_{450}$ was significantly higher for CDN, although the reductions appeared not to be related to MIC values or the concentration:MIC ratio. The heterogeneity in results displayed by the individual isolates could probably be attributed to chemical and physical heterogeneity of specific biofilms (different serotypes), or the results may represent differential gene regulation patterns on a strain basis as has been suggested previously [8]. The significant correlation found in this study between both antibiotics in reducing biofilm development supports this strain basis theory.

The situation was completely different for $H$. influenzae where antibiotics were able to reduce biofilm formation in only 5 of the 12 strains tested. Significantly lower mean $\mathrm{OD}_{450}$ values were obtained compared with controls in the case of CDN but not in the case of AMC. Again, reductions appeared not to be related to the resistance genotype, MIC or the concentration:MIC ratio, although the number of strains tested is too low to draw conclusions.

As expected, lower mean $\mathrm{OD}_{450}$ reductions were obtained in the current study with $\beta$-lactams compared with those obtained with a quinolone in a previous study [8], in part due to the intrinsic physicochemical characteristics of the drugs and 
probably also due to the different methodology used (including the test media) since there is no standard reference methodology, making the results of both studies not comparable. However, the results of the present study may suggest that different $\beta$-lactams have different capabilities of interfering with $S$. pneumoniae biofilm development when tested under the same experimental conditions. Based on this, in addition to the high in vitro bactericidal activity against S. pneumoniae and $H$. influenzae planktonic cells $[7,9]$ exhibiting different resistance phenotypes, CDN may offer the advantage of a higher reduction in biofilm development in $S$. pneumoniae.

\section{Acknowledgments}

The authors acknowledge A. Fenoll (Instituto de Salud Carlos III, Majadahonda, Madrid, Spain) for supply of the pneumococcal strains, and E. Cercenado (Hospital General Universitario Gregorio Marañón, Madrid) and A. Gene (Hospital San Joan de Déu, Barcelona) for the $H$. influenzae strains used in this study.

\section{Funding}

This study was supported in part by an unrestricted grant from Tedec-Meiji Farma S.A., Madrid, Spain.

\section{Competing interests}

PC is an employee of Tedec-Meiji Farma S.A., Madrid, Spain. All other authors declare no competing interests.

\section{Ethical approval}


Not required.

Page 14 of 18 


\section{References}

[1] Donlan RM, Costerton JW. Biofilms: survival mechanisms of clinically relevant microorganisms. Clin Microbiol Rev 2002;15:167-93.

[2] Costerton JW, Stewart PS, Greenberg EP. Bacterial biofilms: a common cause of persistent infections. Science 1999;284:1318-22.

[3] Fux CA, Costerton JW, Stewart PS, Stoodley P. Survival strategies of infectious biofilms. Trends Microbiol 2005;13:34-40.

[4] Prince AS. Biofilms, antimicrobial resistance, and airway infection. N Engl J Med 2002;347:1110-1.

[5] Pérez-Trallero E, García-de-la-Fuente C, García-Rey C, Baquero F, Aguilar L, Dal-Ré R, et al. Geographical and ecological analysis of resistance, coresistance, and coupled resistance to antimicrobials in respiratory pathogenic bacteria in Spain. Antimicrob Agents Chemother 2005;49:1965-72.

[6] Pérez-Trallero E, Marimón JM, Ercibengoa M, Giménez MJ, Coronel P, Aguilar L. Antimicrobial susceptibilities of amoxycillin-non-susceptible and susceptible isolates among penicillin-non-susceptible Streptococcus pneumoniae. Clin Microbiol Infect 2007;13:937-40.

[7] Sevillano D, Giménez MJ, Cercenado E, Cafini F, Gené A, Alou L, et al. Genotypic versus phenotypic characterization, with respect to $\beta$-lactam susceptibility, of Haemophilus influenzae isolates exhibiting decreased susceptibility to $\beta$-lactam resistance markers. Antimicrob Agents Chemother 2009;53:267-70.

[8] Roveta S, Schito AM, Marchese A, Schito GC. Activity of moxifloxacin on biofilms produced in vitro by bacterial pathogens involved in acute exacerbations of chronic bronchitis. Int J Antimicrob Agents 2007;30:415-21. 
[9] Fenoll A, Giménez MJ, Robledo O, Aguilar L, Tarragó D, Granizo JJ, et al. Influence of penicillin/amoxicillin non-susceptibility on the activity of thirdgeneration cephalosporins against Streptococcus pneumoniae. Eur J Clin Microbiol Infect Dis 2008;27:75-80.

[10] Clinical and Laboratory Standards Institute. Performance standards for antimicrobial susceptibility testing. Eighteenth informational supplement. Document M100-S18. Wayne, PA: CLSI; 2008.

[11] Clinical and Laboratory Standards Institute. Methods for dilution antimicrobial susceptibility tests for bacteria that grow aerobically; approved standard. 7th ed. Document M7-A7. Wayne, PA: CLSI; 2006.

[12] Mateo M, Maestre JR, Aguilar L, Giménez MJ, Granizo JJ, Prieto J. Strong slime production is a marker of clinical significance in Staphylococcus epidermidis isolated from intravascular catheters. Eur J Clin Microbiol Infect Dis 2008;27:311-4.

[13] González N, Aguilar L, Alou L, Giménez MJ, Sevillano D, Torrico M, et al. Influence of different resistance traits on the competitive growth of Haemophilus influenzae in antibiotic-free medium and selection of resistant populations by different $\beta$-lactams: an in vitro pharmacodynamic approach. $J$ Antimicrob Chemother 2009;63:1215-22.

[14] Starner TD, Shrout JD, Parsek MR, Appelbaum PC, Kim G. Subinhibitory concentrations of azithromycin decrease nontypeable Haemophilus influenzae biofilm formation and diminish established biofilms. Antimicrob Agents Chemother 2008;52:137-45.

[15] Gilbert P, Brown MR. Biofilms and $\beta$-lactam activity. J Antimicrob Chemother 1998;41:571-2. 


\section{Table 1}

Streptococcus pneumoniae serotypes, minimum inhibitory concentrations (MICs) and percentage reduction in optical density at 450 $\mathrm{nm}\left(\mathrm{OD}_{450}\right)$ compared with controls (in antibiotic-free media) by $0.03 \mu \mathrm{g} / \mathrm{mL}$ cefditoren $(\mathrm{CDN}$ ) and $1 / 0.5 \mu \mathrm{g} / \mathrm{mL}$ amoxicillin/clavulanic acid (AMC)

\begin{tabular}{llllllll}
\hline \multirow{2}{*}{ Strain } & Serotype & \multicolumn{2}{l}{$\mathrm{MIC}(\mu \mathrm{g} / \mathrm{mL})$} & $\mathrm{CDN}$ & \multicolumn{2}{l}{$\mathrm{AMC}$} \\
\cline { 3 - 7 } & & $\mathrm{CDN}$ & $\mathrm{AMC}$ & $\mathrm{OD}_{450}$ (control) & $\% \mathrm{OD}_{450}$ reduction & OD $_{450}$ (control) & \% $_{\text {OD }}$ (50 reduction \\
\hline 1 & 21 & 0.015 & 0.06 & 0.232 & 34.5 & 0.214 & 20.5 \\
2 & $23 \mathrm{~A}$ & 0.015 & 0.06 & 0.130 & 50.5 & 0.105 & 36.7 \\
3 & 31 & 0.03 & 0.12 & 0.092 & 19.2 & 0.090 & 10.4 \\
4 & 42 & 0.06 & 0.25 & 0.210 & 14.7 & 0.235 & 3.3 \\
5 & $35 \mathrm{~B}$ & 0.25 & 1 & 0.080 & 20.1 & 0.086 & 20.9 \\
6 & $6 \mathrm{~B}$ & 0.25 & 2 & 0.095 & 32.9 & 0.089 & 11.2 \\
7 & $23 \mathrm{~F}$ & 0.5 & 2 & 0.101 & 16.3 & 0.087 & 15.6 \\
8 & $19 \mathrm{~A}$ & 0.5 & 2 & 0.084 & 14.8 & 0.078 & 8.5 \\
9 & $9 \mathrm{~V}$ & 0.5 & 2 & 0.091 & 23.5 & 0.088 & 17.0 \\
10 & $9 \mathrm{~V}$ & 0.5 & 2 & 0.088 & 15.2 & 0.084 & 14.9 \\
11 & 14 & 0.5 & 8 & 0.096 & 22.6 & 0.085 & 16.1 \\
\hline
\end{tabular}




\section{Table 2}

Haemophilus influenzae resistance phenotypes, minimum inhibitory concentrations (MICs) and percentage reduction in optical density at $450 \mathrm{~nm}\left(\mathrm{OD}_{450}\right)$ compared with controls (in antibiotic-free media) by $0.03 \mu \mathrm{g} / \mathrm{mL}$ cefditoren $(\mathrm{CDN}) \mathrm{and} 1 / 0.5 \mu \mathrm{g} / \mathrm{mL}$ amoxicillin/clavulanic acid (AMC)

\begin{tabular}{|c|c|c|c|c|c|c|c|}
\hline \multirow[t]{2}{*}{ Strain } & \multirow[t]{2}{*}{ Genotype } & \multicolumn{2}{|c|}{$\mathrm{MIC}(\mu \mathrm{g} / \mathrm{mL})$} & \multicolumn{2}{|l|}{ CDN } & \multicolumn{2}{|l|}{ AMC } \\
\hline & & CDN & AMC & $\mathrm{OD}_{450}$ (control) & $\% \mathrm{OD}_{450}$ reduction & $\mathrm{OD}_{450}$ (control) & $\% \mathrm{OD}_{450}$ reduction \\
\hline 1 & $\mathrm{BL}+$ & 0.03 & 0.5 & 0.098 & 23.1 & 0.075 & 20.0 \\
\hline 2 & $\mathrm{BL}+$ & 0.06 & 8 & 0.098 & 17.4 & 0.103 & -2.2 \\
\hline 3 & BLNAR & 0.06 & 2 & 0.091 & 12.9 & 0.082 & 18.0 \\
\hline 4 & BLPACR & 0.06 & 4 & 0.107 & 9.5 & 0.091 & 4.5 \\
\hline 5 & BLNAR & 0.06 & 16 & 0.085 & 6.1 & 0.080 & 6.7 \\
\hline
\end{tabular}

$\mathrm{BL}+, \beta$-lactamse-positive; BLNAR, $\beta$-lactamase-negative ampicillin-resistant; BLPACR, $\beta$-lactamase-positive amoxicillin/clavulanic acid-resistant. 